\title{
A Review on Speed Control of Induction Motor Drives
}

\author{
Patel Pinkal Raghubhai \\ Assistance Faculty, Elect. Department, Rustomjee Acedamy for Global Careeres, Dahanu
}

\begin{abstract}
Induction motors are the most widely used electrical motors due to their reliability, low cost and robustness. However, induction motors do not inherently have the capability of variable speed operation. Due to this reason, earlier $\mathrm{dc}$ motors were applied in most of the electrical drives. But the recent developments in speed control methods of the induction motor have led to their large scale use in almost all electrical drives. Out of the several methods of speed control of an induction such as pole changing, frequency variation, variable rotor resistance, variable stator voltage, constant V/f control, slip recovery method etc., the closed loop constant V/f speed control method is most widely used. In this method, the V/f ratio is kept constant which in turn maintains the magnetizing flux constant so that the maximum torque remains unchanged. Thus, the motor is completely utilized in this method. During starting of an induction motor, the stator resistance and the motor inductance (both rotor and stator) must be kept low to reduce the steady state time and also to reduce the jerks during starting. On the other hand, higher value of rotor resistance leads to lesser jerks while having no effect on the steady state time. The vector control analysis of an induction motor allows the decoupled analysis where the torque and the flux components can be independently controlled (just as in dc motor). This makes the analysis easier than the per phase equivalent circuit.
\end{abstract}

Keyword: speed control, induction motor, torque speed analysis, different methods, drive.

\section{INTRODUCTION}

Be it domestic application or industry, motion control is required everywhere. The systems that are employed for this purpose are called drives. Such a system, if makes use of electric motors is known as an electrical drive. In electrical drives, use of various sensors and control algorithms is done to control the speed of the motor using suitable speed control methods. The basic block diagram of an electrical drive is shown below:

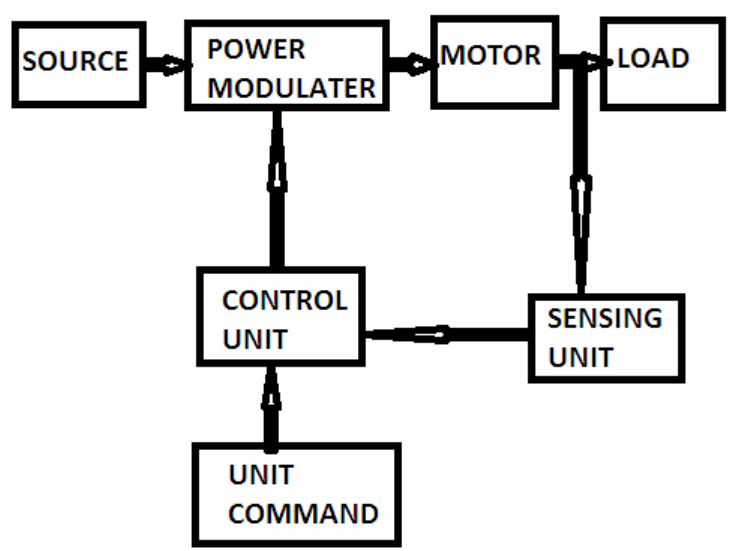

Fig. 1 Block diagram of an electrical drive

Earlier only dc motors were employed for drives requiring variable speeds due to ease of their speed control methods. The conventional methods of speed control of an induction motor were either too expensive or too inefficient thus restricting their application to only constant speed drives.
However, modern trends and development of speed control methods of an induction motor have increased the use of induction motors in electrical drives extensively.

THREE PHASE INDUCTION MOTOR

Based on the construction of the rotor, a 3-phase induction motor can be categorized into two types:

i. Squirrel Cage Induction Motor

ii. Wound Rotor or Slip Ring Induction Motor

The stator of both types of motors consists of a three phase balanced distributed winding with each phase mechanically separated in space by 120 degrees from the other two phase windings. This gives rise to a rotating magnetic field when current flows through the stator. In squirrel cage IM, the rotor consists of longitudinal conductor bars which are shorted at ends by circular conducting rings. Whereas, the wound rotor IM has a 3phase balanced distributed winding even on the rotor side with as many number of poles as in the stator winding.

\section{WORKING PRINCIPLEOF THREE PHASE INDUCTION MOTOR}

When a three phase supply is given to the three phase stator winding, a magnetic field of constant magnitude and rotating at synchronous speed $\mathrm{Ns}$ is produced. This rotating magnetic field sweeps across the rotor conductors and hence an electromagnetic force (EMF)is induced in rotor conductors. As the rotor conductors are short circuited on themselves the induced EMF sets up a current 
in the rotor conductors in such a direction as to produce a torque, which rotates the rotor in same direction as magnetic field so that relative speed decreases. The speed of rotor gradually increases and tries to catch up with the speed of rotating magnetic field, but it fails to reach synchronous speed, because if it catches up with speed of magnetic field, relative speed becomes zero and hence no EMF will be induced in the rotor conductors, the torque becomes zero. Hence, rotor willnot be able to catch up with the speed of magnetic field but rotates at a speedNrwhich isslightly less than the synchronous speed.The speed of the induction motor is given by,

$$
N=\frac{120 f}{P}
$$

\section{DIFFERENT SPEED CONTROL METHODS}

From the above equation, the speed of the motor can be controlled by changing supply frequency and by changing number of poles in the stator.it consist two method: scalar method and vector method. The scalar method are classified as:

\section{Control from Stator Side:}

- By changing the supply frequency

- By changing number of stator poles

- By changing the supply voltage

- Volts Hertz (V/F) control method

\section{Control From Rotor Side:}

- By inserting resistance in rotor circuit

- By various ways of cascade connection

- By injecting EMFs in the rotor circuit.

\section{SPEED CONTROL BY FREQUENCY VARIATION:}

- By varying supply frequency (on small amount), we can vary the speed.

- But a decrease in supply frequency decreases the speed and increases the flux, core losses which leads heating and low efficiency.

- Increase in frequency increases the speed and reduces the torque.

- A separate costlier auxiliary equipment is required to provide a variable frequency.

- So this method is not used in practical.

\section{SPEED CONTROL BY POLE CHANGING:}

- The change of number of poles is done by having two or more entirely independent stator windings in the same slots.

- Each winding gives a different number of poles, so we will get different speeds.

- Due to cost and complex switching arrangements, it is not practical to provide more than two arrangements of poles (ie, two normal speeds).

- This method is applicable to squirrel cage induction motor only.

- It is not practically applicable with wound rotor.

\section{SPEED CONTROL BY VARYING SUPPLY} VOLTAGE:

Three area interconnected power system:

Three interconnected area considered in this paper are:

Area-1 is reheat thermal plant Areaa-2 is also reheat thermal plant and Area-3 is hydro plant. All these three area are interconnected with tie line.in hydro area the electrical governor is used.

- The speed of induction motor can be varied by changing supply voltage.

- The torque developed in this method is proportional to the square of the supply voltage. $\mathrm{T} \propto \mathrm{V}^{2}$

This is the cheapest and easiest method, but it is rarely used because of the below reasons.

1. A small change in speed requires a large change in voltage.

2. This large change in voltage will result in a large change in the flux density.

\section{VOLTS HERTZ (V/F) CONTROL METHO}

The constant V/F control method is the most popular method of Scalar control. If an attempt is made to reduce the supply frequency at the rated supply voltage, the air gap flux $\Psi \mathrm{m}$ will tend to saturate, causing excessive stator current and distortion of flux wave. Therefore, the region below the base or rated frequency should be accompanied by the proportional reduction of stator voltage so as to maintain the air gap flux constant. If the ratio of voltage to frequency is kept constant, the flux remains constant. By varying the voltage and frequency the torque and speed can be varied. The torque is normally maintained constant while the speed is varied. This arrangement is widely used in the locomotives and industrial applications. The purpose of the volts hertz control scheme is to maintain the air-gap flux of AC Induction motor constant in order to achieve higher run-time efficiency. The magnitude of stator flux is proportional to the ratio of stator voltage \& the frequency. If ratio is kept constant the stator flux remains constant \& motor torque will only depends upon slip frequency. In variable - frequency, variable-voltage operation of a drive system, the machine usually has low slip characteristics (i.e low rotor resistance), giving high efficiency. In spite of the low inherent starting torque for base frequency operation, the machine can always be started at maximum torque as indicated in Fig 3.8.The absence of high in-rush starting current in a direct-start drive reduces stress and therefore improves the effective life of the machine.By far the majority of variable-speed ac drives operate with a variable-frequency, variablevoltage power supply.

SPEED CONTROL BY VARYING ROTOR RESISTANCE:

- This method is applicable to three-phase slip-ring induction motor only. 


\section{International Journal of Innovative Research in Electrical, Electronics, Instrumentation and Control Engineering ISO 3297:2007 Certified \\ Vol. 5, Issue 2, February 2017}

- By introducing external resistance in the rotor circuit, the speed of the motor can be reduced.

- The change in speed depends upon both rotor circuit resistance and load.

- Due to power loss in the resistance, this method is used where speed changes are required for short period only.

- This method is similar to armature rheostat control method of DC shunt motors.

\section{SPEED CONTROL BY INJECTED EMF:}

- Instead of applying the resistance into the rotor circuit of the motor, the speed can be varied by applying EMFs into the circuit.

- These EMFs are applied at the rotor by a suitable source whose frequency should be same as slip frequency.

- Inserting the EMF in phase with the rotor induced EMF is equivalent to decreasing the rotor resistance.

- Inserting the EMF in phase opposition to the induced rotor EMF is equivalent to increasing its resistance.

- Thus by injecting EMF into the rotor the speed can be controlled.

\section{SPEED CONTROL BY CASCADE CONNECTION:}

- This method needs two motor, one of them is wound motor.

- The two motors are mechanically coupled together to drive a common load.

- The starter of slip ring induction motor is connected to three-phase supply and its rotor is connected to stator of the other machine.

There are four possible speeds can be obtained by this arrangement.

$$
\begin{aligned}
& N=\frac{120 f}{P 1} \\
& N=\frac{120 f}{P 2} \\
& N=\frac{120 f}{P 1+P^{2}} \\
& N=\frac{120 f}{P 1-P^{2}}
\end{aligned}
$$

Where $\mathrm{f}=$ supply frequency

$\mathrm{P} 1=$ No of poles in slip ring motor

$\mathrm{P} 2=$ No of poles in other motor

\section{CONCLUSION}

After literature reviewing conclude that in rotor resistance control method the starting torque can be varied with the variation of rotor resistance. The maximum torque however, remains unaffected. Thus for operations requiring high starting torque, the rotor resistance can be varied to even obtain the maximum torque during starting. But simultaneously the copper losses will increase due to increase of resistance. So this method is highly inefficient and cannot be used throughout the operation.

In variable supply voltage control method of speed control, the maximum torque decreases with the decrease of supply voltage and thus the motor remains underutilized. So even this method cannot be used for good performance.

In constant control, by use of rectifier and PWM inverter, we can vary the supply voltage as well as the supply frequency such that the ratio remains constant so that the flux remains constant too. So we can get different operating zone for various speeds and torques and also we can get different synchronous speed with almost same maximum torque. Thus the motor is completely utilized and also we have a good range of speed control.

\section{REFERENCES}

[1] Gopal K. Dubey, "Fundamental of Electrical Drives", Narosa Publication House, Second Edition, 2011

[2] A. E. Fitzgerald, Charles Kingsley, Jr. And Stephan D. Umans, "Electrical Machinery", McGraw-Hills Publications, Year 2002 [3] "IEEE Standard Test Procedure for Polyphase Induction Motors and Generators", volume 112, issue 1996 of IEEE, by IEEE Power Engineering Society

[4] Scott Wade, Matthew W. Dunnigan, and Barry W. Williams, "Modelling and Simulation of Induction Machine Vector Control with Rotor Resistance Identification", IEEE transactions on power electronics, vol. 12, no. 3, may 1997.

[5] D.W. Novotney, et al (editor), "Introduction to Field Orientation and High Performance AC drives", IEEE IAS tutorial course, 1986.

[6] Ramon Blasco Blasco Gimenez, "High Performance Sensorless Vector Control of Induction Motor Drives", The University of Nottingham, December 1995.

\section{BIOGRAPHY}

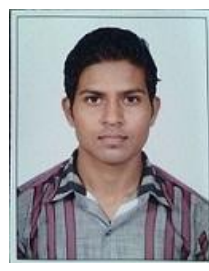

Patel Pinkal Raghubhai received his B.E degree from Gujarat technological university, Ahmedabad in Electrical Engineering In 2015. At present he is working with Rustomjee Academy for Global Careers as Assistant Faculty in Electrical Department. 